\title{
¿DERECHO INTERNACIONAL DEL COMERCIO, DERECHO DEL COMERCIO INTERNACIONAL O DERECHO DEL COMERCIO EXTERIOR?*
}

\section{Rodolfo CRUZ MIRAMONTES**}

\begin{abstract}
RESUMEN: El presente trabajo transcribe la ponencia presentada con motivo del ingreso a la Academia Mexicana de Jurisprudencia y Legislación del doctor Rodolfo Cruz Miramontes, y la contestación que al primero da el profesor José Luis Siqueiros. El contenido de ambas participaciones muestra un panorama general y evolutivo de la normatividad y práctica comercial a nivel internacional; llegando a reflexiones en torno al desarrollo del derecho económico como rama del derecho internacional público, y al surgimiento aún no consolidado del derecho del comercio internacional como rama independiente del primero.
\end{abstract}

ABSTRACT: This article transcribes both the paper presented by doctor Rodolfo Cruz Miramontes when admitted to the Mexican Academy of Jurisprudence and Legislation and the paper presented by professor Jose Luis Siqueiros on answering the former. The contents in both of them show a general overview and evolution of commercial law and practice at the international level; in doing so, they reflect on the development of economic law as part of Public International Law as well as on the emergence of a non-consolidated independent branch of law as yet: the Law of International Commerce.

RÉSUMÉ: Le présent travail transcrit l'exposé présenté à l'occasion de l'intégration formel du docteur Rodolfo Cruz Miramontes à l'Académie Mexicaine de Jurisprudence et de la Législation ainsi qu'en réponse à l'intervention préalable effectuée par le professeur José Luis Siqueiros. Le contenu des deux participations montre un panorama général et évolutif de la normativité ainsi que de la pratique commerciale au niveau mondial. Leur raisonnement aboutit à dégager des réflexions autour de la question du développement du droit économique comme branche de la législation internationale Publique et à l'apparition, encore non consolidée, de la législation du Commerce International comme branche autonome.

* Ponencia de ingreso a la Academia Mexicana de Jurisprudencia y Legislación el 25 de octubre de 2005.

** Doctor en derecho, socio de Cruz abogados, S. C., y profesor de derecho comercial internacional en la Universidad Iberoamericana. 
SUMARIO: I. Antecedentes. II. El derecho económico. III. ¿Derecho internacional del comercio o derecho del comercio internacional o derecho del comercio exterior? IV. Caracteristicas de las normas comerciales internacionales. V. Conclusiones. VI. Anexo.

Seleccionar un tema que responda a la categoría del acto que hoy nos convoca, constituye un reto serio. El índice de disertaciones que se han presentado para ingresar como miembros de número a esta noble institución, abarcan una multiplicidad de objetos de análisis que reflejan sin duda las inquietudes científicas de sus autores, tal como es mi caso el día de hoy.

$\mathrm{Al}$ impulso anterior he considerado un ingrediente adicional para intentar aportar algo a nuestra ciencia del derecho, acorde con las exigencias de la época, en donde estamos enfrentando áreas de quehacer con un alto contenido económico propio de instituciones recién incorporadas a nuestro sistema administrativo pero lógicamente poco exploradas por nuestros estudiosos.

El fenómeno es común en nuestro continente, particularmente en los países hispanoamericanos regulados por el sistema románico por lo que es indispensable adentrarnos en ellos y su necesario conocimiento deviene cada día más pertinente.

Poco se está haciendo a nivel latinoamericano para su difusión, y por ello la profesora argentina Zlata Drnas de Clément, se quejaba de que en nuestras universidades no existen cursos sobre estos temas. ${ }^{1}$ Cabe consignar que admite algunas excepciones pues hace mención a los cursos que en algunas universidades hispanoamericanas se imparten sobre el tema, ubicando en forma destacada al que dicto en la Universidad Iberoamericana desde hace ya más de una década. ${ }^{2}$

En nuestro país, algunos profesores universitarios se han venido ocupando de materias vinculados al derecho económico, particularmente en los años sesenta, y he tenido la oportunidad de impartir un curso al que denominé "Derecho de la integración económica" en el diplomado que sobre derecho financiero se estableciera en la Facultad de Derecho de la UNAM, merced a la visión que tuvo sobre la importancia de estos

1 "La enseñanza aprendizaje del derecho comunitario en América", Anuario Argentino de Derecho Internacional, Córdoba, Argentina, 1992-1993, t. V.

2 Ibidem, p. 273. 
temas, su entonces secretaria general doctora Yolanda Frías de grata memoria, y quien tuvo la amabilidad de ofrecerme la materia en cuestión lo que siempre le he agradecido.

Gracias a ello he continuado navegando en estas procelosas aguas tratando de entender sus múltiples vericuetos, lo cual permite compartir mis inquietudes no sólo con mis alumnos sino también participar en lo posible, en las tareas que nuestro país ha emprendido desde entonces al negociar numerosos acuerdos regionales de comercio y afrontar diversas controversias en órganos arbitrales creados para su resolución.

Siendo muchas las interrogantes que en nuestro campo de acción profesional se plantean, desde la primera ocasión en que me ocupé académicamente del tema, apareció una muy precisa y muy clara: ¿existe un derecho internacional de la integración o más concretamente, del comercio así como hay un derecho marítimo internacional por ejemplo? o más bien iSe trata de un derecho del comercio internacional subordinado y dependiente del derecho económico? o por contra iforma parte del derecho internacional público (DIP)?

Resulta a mi ver cada día más pertinente encontrar respuestas a todas las interrogantes que van surgiendo en la medida en que se van presentando, por lo que intentaré conocerlas o al menos acercar algunas posibles respuestas. Este esfuerzo será el contenido de mi ponencia.

\section{ANTECEDENTES}

Debemos considerar que ya van más de ochenta años que fue planteado un cuestionamiento similar sobre el llamado derecho económico, por lo que me permitiré hacer una referencia sucinta a esta situación, pues considero que dicha disciplina en alguna forma se encuentra cercana a las disposiciones que siendo económicas se aplican a cuestiones comerciales internacionales.

Sin desconocer que algunos principios que ahora son pilares del comercio internacional ya se aplicaban desde hace más de 150 años como sucede con el de la nación más favorecida (NF), ${ }^{3}$ la consagración universal y utilización del mismo se dará hasta mediados del siglo XX.

3 Merece una mención por su rareza el Tratado de Amistad, Navegación y Comercio entre México y los Estados Unidos de América, 5 de abril de 1831, cuyo artículo Ilo. textualmente dice: "Los Estados Unidos Mexicanos y los Estados Unidos de América deseando tomar por base de este 
Dicha consagración aparece en el artículo Io. del Acuerdo General de Aranceles Aduaneros y Comercio (GATT), y desde la entrada en vigor del mismo, se aplica prácticamente en todas las transacciones comerciales internacionales y se recoge también en acuerdos multilaterales y bilaterales. Desde luego, la Organización Mundial de Comercio (OMC) la consignó en su anexo número 1 y el Acuerdo Latinoamericano de Integración (Aladi) en su artículo 44.

Sin lugar a dudas que en los últimos veinte años la proliferación de tratados comerciales ha creado estatutos jurídicos particulares y algunos de ellos se han extendido más allá de su campo original hacia terceros países y aún a otros continentes. El ejemplo más concreto nos lo da el acuerdo global que celebramos con la Unión Europea vigente desde mediados del 2001. ${ }^{4}$ Por lo que toca a los acuerdos regionales cuyo contenido es evidentemente comercial bastará citar entre otros, al Acuerdo Europeo de Libre Comercio (EFTA), los Acuerdos de Lomé y Yahondé que tienen como sujetos a países europeos y a sus ex colonias, y por supuesto consignaremos a los doce acuerdos de los que México es parte.

Todos estos compromisos internacionales generan derechos y obligaciones con señalado impacto en la comunidad internacional; eventualmente causan discrepancias en su aplicación y han sido fuente, en muchas ocasiones, de sistemas propios para atender y dirimir las mismas aplicándose desde luego en su área de competencia.

Cabe preguntarnos nuevamente a la luz de estos hechos, si el conjunto de normas surgidas de estos acuerdos caen dentro del ámbito nada más del derecho económico o constituyen capítulos jurídicos diversos y si así fuese ¿en dónde lo colocamos?

Como se puede apreciar, esta situación no sólo se presenta atractiva para el académico sino también para el político y para quien practica la materia comercial internacional.

Al intentar conocer la esencia de los conceptos que abarcan las normas en cuestión, nos encontramos que desde hace tiempo aparecen en el

convenio la más perfecta igualdad y reciprocidad, se comprometen mutuamente a no conceder ningún favor particular a otras naciones en lo respectivo a comercio y navegación que no venga a ser inmediatamente común a la otra parte, la cual deberá gozarlo libremente, si la concesión fue hecha libremente, o bajo las mismas condiciones si la concesión fuese condicional".

4 El embajador Javier Solana, Alto Representante de la Política Exterior de la UP, opina a propósito: "El Acuerdo de la Asociación, el primero firmado por la Unión Europea con cualquier país o grupo de países de Iberoamérica, ha permitido dinamizar y profundizar la relaciones bilaterales en beneficio mutuo", Reforma, 26 de mayo del 2005, p. II. 
sistema del Common Law debido a que históricamente surgieron y se consideraron instituciones propias en países sajones, pero ahora ante el fenómeno de la globalización, debemos conocerlas y acomodarlas en los sistemas del derecho romano-germánico.

La tarea no es simple más deviene necesaria, y este esfuerzo espero que justifique al menos mi ingreso a esta augusta institución en donde ocuparé el sitial número 26 que tan ilustres juristas lo han detentado con anterioridad, como es el caso de don Pedro Lascurain y del maestro Ignacio Burgoa.

El reacomodo de la comunidad internacional al fin de la Primera Guerra Mundial dio pie a que se desarrollasen diversos campos industriales y agrícolas en los que destacó el factor económico, y a que desde luego, se promulgasen disposiciones legales para regularlas. Indudablemente que los gobiernos afectados por los acontecimientos bélicos estuvieron conscientes de que factores de esta naturaleza jugaron también entre otras causas, un papel de gran peso en el estallido de la Segunda Guerra Mundial.

\section{EL DERECHO ECONÓMICO}

Los analistas que se han ocupado del tema, no vacilan en señalar en forma coincidente que la preocupación por ubicar y catalogar a este conjunto de reglas que se aplicaban a una realidad novedosa, se dio en Alemania (Internationale Wirtshaftsrecht): "Fue durante el periodo transcurrido entre las dos guerras mundiales cuando la idea de la democracia económica recibió un principio de consagración constitucional en Europa (Constitución soviética, de la República de Weimar, etcétera), y más tarde este movimiento se amplió por las crisis económicas de 1929 y $1930 " .5$

Los brotes simultáneos de problemas económicos y sociales no solamente en la Europa de la postguerra sino en otros países como en los Estados Unidos de América desembocaron en revisiones y reestructura-

5 Cuadra, Héctor, "Reflexiones sobre el derecho económico", Estudios sobre derecho económico I, México, UNAM, 1977, vol. I, pp. 32-38 y 39. El profesor Gerard Farjat nos recuerda que uno de los primeros autores que se ocuparon del tema fue J. Hedeman en su obra Grumdgûge des Wirtshaftsrecht, 1922 (Droit Economique, Thémis, 1971, p. 22). En igual sentido, Cottely, Esteban, "Derecho económico", Lecturas Universitarias, México, UNAM, núm. 288, 1978, pp. 17 y 18 . 
ciones en todos los campos de la economía tanto nacional como internacional.

Las tesis opuestas entre los sistemas del mercado controlado, cerrado, frente a la contraria de libre mercado en donde el Estado juega un papel diferente, se hicieron cada vez más relevantes.

Los politólogos y sobre todo los juristas han señalado con claridad criterios a considerar para buscar salidas útiles y sobre todo fundadas en una concepción trascendente del Estado.

El maestro Héctor Fix -Zamudio considera que:

El Estado debe vigilar que el crecimiento considerado como algo deseable a priori, sea regular, continuo, armónico y generalizado... Por otra parte el Estado debe prevenir o reducir las tensiones sociales puesto que la evolución espontánea de la economía liberal conduce a desequilibrios crecientes entre sectores económicos o entre regiones.

A esta aplicación del papel del Estado ha correspondido, naturalmente, una transformación de las instituciones políticas y una evolución del derecho. ${ }^{6}$

Mencionemos también la opinión del profesor Pierre Pescatore por su claridad y precisión: "el proceso de integración sólo puede tener una consistencia real, y sobre todo estabilidad y duración, si logramos darle una armazón institucional y jurídica suficientemente sólida". ${ }^{7}$

La existencia del sistema soviético ejerciendo un control y dominio sobre la propiedad de los bienes de producción, la socialización de la agricultura, los controles a las actividades de las empresas fundamentalmente del gobierno, la regulación de las actividades laborales y otras manifestaciones más de la presencia del Estado en este amplio sector, creó sin duda, un cuerpo legal normativo de todas estas actividades y de ahí que para algunos analistas, el derecho económico existente en el conjunto de países socialistas vino a conformar un claro capítulo de un nuevo derecho.

Cabe preguntarnos si aparte de estas actividades reguladas jurídicamente en los países del bloque socialista, no existen otros órdenes legales

6 "Presentación", Estudios de derecho económico I, México, UNAM, 1976, pp. 6 y 7.

7 Derecho de la integración: nuevo fenómeno de las relaciones internacionales, trad. de Inés Carmen Matareese, Buenos Aires, BID-INTAL, 1973, p. 2. 
que también se ocupan de actividades similares en sistemas políticos y jurídicos distintos.

Constituye un fenómeno innegable que fuera del área consignada, el Estado también ha venido tomando parte en los campos económicos por razón fundamentalmente de beneficio social y de protección a los sectores más desprotegidos bien en el campo o en la producción industrial urbana.

A partir de los movimientos comprendidos bajo términos como emergentes, o de países en vías de desarrollo, y otros similares, se dieron fenómenos de presencia estatal marcada que sin estar dentro del ámbito del socialismo ortodoxo, se acercaban al mismo en preocupaciones para proteger a ciertas capas sociales, lo que vino a conformar un cúmulo de normas legales novedosas. De ahí se origina la división del mundo en dos segmentos: el desarrollado y el subdesarrollado, según opina Celso Lafer, generándose un conjunto de normas jurídicas bajo el amparo del derecho económico que comprende, según Georges Schwarzenberger, los siguientes:

1) La propiedad y la explotación de los recursos naturales

2) La producción y la distribución de bienes

3) La moneda y las finanzas

4) La propiedad y explotación de recursos naturales

5) Las transacciones internacionales y otros ${ }^{8}$

Dentro del ámbito típicamente capitalista también encontramos una evolución en la detentación de la propiedad de los bienes y de la producción de insumos, cuyo tránsito, dicho en forma muy simple, pasó de la propiedad privada a una forma general y colectiva, cuyo extremo lo podemos ubicar actualmente en los grandes consorcios sean llamados holdings o empresas transnacionales; lo que para algunos estudiosos se trata del capitalismo de los monopolios y de los oligopolios.

Como fuere en ambos sistemas, relativos a los bienes y a la producción, su control se centraliza en las manos de entes concretos bien se trate de órganos estatales de carácter público o particular de gran envergadura, totalmente alejados de la propiedad individual tradicional.

8 Schwarzenberger, Georges, "Comercio internacional: fórmulas jurídicas y realidades político económicas", Derecho internacional económico, México, FCE, 1974, p. 28. Asimismo, véase Miaja de la Muela, Adolfo, Principios y reglas fundamentales del nuevo orden económico internacional, Madrid, IHLADI, 1976. 
Llama la atención que hayan sido economistas estdounidenses en particular, quienes de manera destacada hayan reparado en estos hechos aparecidos en los Estados Unidos de América y también en otros países de la órbita capitalista como Alemania, Francia y Gran Bretaña. ${ }^{9}$

No podemos desde luego dejar de reparar que esta presencia de fenómenos, trasciende más allá de las fronteras nacionales y en cierta forma, aparecen en las relaciones internacionales sobre todo al finalizar la Segunda Guerra Mundial y en los ordenamientos que se llevaron a cabo, de todo el sistema económico y financiero posterior a este lamentable episodio bélico, tal como había sucedido con su predecesor.

Los programas numerosos y variados que se establecieron para reconstruir los países devastados y generar empleos en búsqueda de impulsar la economía en todos los órdenes, tanto internos como internacionales, vinieron a conformar otras expresiones estatales que dieron nacimiento a reglas jurídicas ya no sólo de marcado acento económico sino ahora mayormente de carácter comercial y financiero.

Programas tales como el Plan Marshall, el Plan Truman, el dedicado a levantar a Grecia y a Turquía, el denominado UNRRA (United Nationas Relif and Rehabilitation Administration) aplicable a Japón y a Europa Occidental, el relativo a los préstamos a favor de la Gran Bretaña y otros más, fueron la cuna de todo un sistema creado en Bretton Woods y desarrollado a través de instituciones como el Banco Mundial de Reconstrucción y Fomento (Banco Mundial) el Fondo Monetario Internacional (FMI) y posteriormente el Acuerdo General de Aranceles Aduaneros y Comercio (GATT). ${ }^{10}$

Como es de suponerse estas instituciones promulgaron reglas y disposiciones aplicables a sus miembros o partes contratantes como se denominan a los del GATT y han sido venero de muchas más de carácter multilateral así como de acuerdos de la misma naturaleza cuyo más acabado producto al día de hoy lo constituye sin duda, la Organización Mundial de Comercial (OMC).

9 Nos referimos particularmente a John K. Gallbraigth y a Adolf A. Berle.

10 Desde luego, el proyecto elaborado para crear la Organización Internacional de Comercio (OIC) jugó un papel definitivo, pero al no haberse aprobado por el congreso estadounidense, nunca entró en vigor; los programas referidos y los tres pilares del Sistema de Bretton Woods sostuvieron la reordenación económica mundial. Véase The Restoration of International Trade, Nueva York,, Carnegie Endowment for International Conciliation, octubre de 1947. 
Dado que estamos ocupándonos de las relaciones entre miembros de la comunidad internacional, será útil a nuestro análisis recordar que tradicionalmente se considera la presencia en el derecho internacional público de dos grandes momentos o pautas precisas: el de la coexistencia desde su creación en el siglo XVI hasta la postguerra de la Segunda Guerra Mundial y el de la cooperación internacional a partir del establecimiento de la Organización de las Naciones Unidas (ONU). ${ }^{11}$

Sin desconocer la presencia de matices varios y tal vez nuevas experiencias como la globalización económica, la tesis de la guerra preventiva promovida por el gobierno estadounidense que constituye la negativa al derecho internacional y otras más, estimo que las caracterizaciones señaladas de coexistencia y cooperación son válidas y que están presentes actualmente en la comunidad internacional pero al mismo tiempo presentando orientaciones y tendencias acordes con las exigencias de la época. "Una nueva dimensión de las relaciones internacionales desde el fin de la última Guerra Mundial, es el interés en el desarrollo económico internacional", afirma el profesor Wolfgang Friedman.

Y el profesor Colliard añade que: "el derecho internacional no es ya simplemente un derecho de coexistencia entre estados limitados a sus relaciones; se ha convertido en un derecho finalista, en un marco necesario a la política económica de desarrollo y de aprovechamiento". ${ }^{12}$

Algunos de los jus-internacionalistas más destacados actualmente, dan cabida sin reparo en sus textos a la presencia del factor económico en el desarrollo del derecho internacional como ya hemos mencionado, a los que podemos añadir algunos profesores escogidos al azar como son: Manuel Diez de Velazco, Alfonso Miaja de la Muela, Antonio Aguilar Navarro, Alfred Verdross, Paul Reuter, Charles Vischer, Kovar, Champaud, Héctor Gross Espiel y otros más.

En nuestro país, el reconocimiento a la importancia del tema económico y su necesaria regulación, fue oportuna y muy bien definida; así lo acredita sin duda el que México haya propuesto y cabildeado la Carta de

11 Siendo muy numerosos los estudios sobre el tema, sólo a guisa de ejemplo mencionaré los siguientes: Sepúlveda César, El derecho de gentes y la organización internacional en los umbrales del siglo XXI, México, UNAM-FCE, 1995; Kunz, Josef L., Del derecho internacional clásico al derecho internacional nuevo, México, UNAM, Facultad de Derecho, 1953; Del Vecchio, Giorgio, El derecho internacional y el problema de la paz, Barcelona, Bosch, 1959.

12 Friedman, Wolfgang, La nueva estructura del derecho internacional, México, Trillas, 1967, p. 433 . 
los Derechos y Deberes Económicos de los Estados para que fuera adoptada por las Naciones Unidas el 12 de diciembre de 1974.

El siempre bien recordado maestro César Sepúlveda que fuera miembro distinguido de esta academia, le dedica en su ya tradicional texto Derecho internacional, varias páginas al tema del derecho económico y a la aludida carta en cuya redacción presumiblemente participó.

Añadamos al nombre del maestro Sepúlveda los de otros distinguidos maestros como Jorge Witker y Héctor Cuadra quienes no sólo han publicado estudios y análisis sobre el tema, sino además han promovido seminarios y tareas colectivas académicas para considerar diversos aspectos del derecho económico.

Por todo lo dicho coincidimos con la opinión generalizada de que existe un reciente capítulo del derecho internacional público denominado derecho económico internacional que tiene también su presencia en el derecho interno. ${ }^{13}$

\section{III. ¿DERECHO INTERNACIONAL DEL COMERCIO O DERECHO DEL COMERCIO INTERNACIONAL O DERECHO DEL COMERCIO EXTERIOR?}

Visto lo anterior volvamos al tema central de nuestras pesquisas sobre un posible derecho comercial internacional o un derecho del comercio internacional como lo he denominado.

No siendo original esta cuestión, tenemos varias opiniones sobre el particular, algunas coincidentes y otras no, pero todas ellas concuerdan en que desde 1947 se viene conformando un conjunto de reglas jurídicas con marcada presencia de elementos comerciales y financieros.

Algunos profesores especialistas como por ejemplo el doctor Alfonso Insuela Pereira y el profesor Darío Munera Arango sostienen que el derecho económico internacional y el derecho comercial internacional

13 Algunos especialistas llegan a considerar la existencia inclusive de normas económicas propias a una región del mundo como el doctor White, Eduardo, El derecho económico en América Latina, Caracas, Editorial Jurídica Venezolana, 1977; Brito, M., Derecho internacional económico, México, Trillas, 1982. El respetable maestro don Jorge Barrera Graf, de tan grata memoria, se planteó una interrogante similar, pero su inquietud se refirió particularmente a los contratos internacionales de mercaderías, como se desprende de su obra La reglamentación uniforme de las compraventas internacionales de mercaderías, México, UNAM, 1965, cuyo primer capítulo lo denominó: "Hacia un derecho internacional del comercio". 
son dos órdenes jurídicos diversos que si bien presentan relaciones estrechas entre sí, no se deben confundir.

Tajantemente, Insuela Pereira afirma que: "O Direito Económico, pois nao se confunde com Direito Comercial. Antes, abarca-o por ser este, em último análise, um setor daquale, más ampro". ${ }^{14}$

Otros especialistas sostienen la posición contraria. En un trabajo analítico por demás sugerente, muy bien armado que ya hemos utilizado, el profesor Prosper Weil de la Universidad de París, lleva a cabo una revisión amplia de múltiples facetas del derecho económico y nos presenta las opiniones de quienes en forma destacada se habían ocupado al momento del tema referente a la existencia autónoma del mismo.

En su tercera conclusión afirma que: "El carácter económico de las materias referentes no constituye sino un simple coeficiente incapaz de dar nacimiento a una disciplina autónoma, a un cuerpo de derecho distinto... En el plano científico, el derecho internacional económico no constituye sino un capítulo entre otros del derecho internacional general". ${ }^{15}$

$\mathrm{Al}$ referirse a la relación entre derecho internacional económico y derecho internacional general sostiene que: "la mayoría de las relaciones humanas se sitúan fuera del derecho y dependen de las relaciones de dominación (fuerza, prestigio, influencia) o de reglas morales no traspuestas en obligaciones jurídicas". ${ }^{16}$

Desde nuestro punto de vista, lo anterior contiene una óptica del derecho con la que no concordamos, por lo que resulta imprescindible explicar qué es lo que entendemos por derecho, para así darle sentido y congruencia a las conclusiones a las que arribemos más adelante.

\section{La ciencia del derecho}

Para poder iniciar esta segunda parte de las presentes indagaciones, estimo necesario ocuparme primeramente de establecer cuál es, en mi perspectiva, el concepto del derecho, cuál su ámbito de aplicación y cuáles sus limitaciones.

Esto servirá como una antesala para acceder a los considerandos relativos a la cuestión central planteada.

14 Insuela Pereira, Alfonso, $O$ Direito Economico na Ordem Jurídica, São Paulo, José Bushatsky, 1974, pp. 129-122.

15 Derecho internacional económico: ¿mito o realidad?..., cit, p. 211.

16 Ibidem, p. 202. 
Sería ocioso adentrarnos en discusiones profundas y amplias sobre la definición del derecho, además muy riesgoso para mí ante maestros expertos en el tema.

Solamente me limitaré, pues, a formular mi visión con absoluta convicción de lo que estimo es el derecho y a la que me he apegado, con lealtad, durante mi vida profesional.

Acorde con las lecciones de mi admirado maestro don Óscar Morineau, el derecho es una ciencia social que como tal, persigue alcanzar valores de esta naturaleza tales como el orden, la certeza, la seguridad, la legalidad, la convivencia, y en lo que sea posible, la justicia a efectos de lograr que el individuo, el ser humano, pueda realizarse plenamente pero siempre con responsabilidad frente a la sociedad y a las personas en lo individual.

Por esto considero que la conducta externa del hombre, del ciudadano, está regida en su integridad por el derecho, y que no hay un acto que no lo esté.

El Estado a su vez descansa y aplica un orden jurídico acorde con su proyecto de nación, facilitando así al ciudadano su realización personal para acceder al bien común.

Desde luego concurren en estas tareas otras ciencias como la ética que se ocupa de la conducta interna del hombre y que debe coincidir como sería deseable con la externa del mismo. Adicionalmente tenemos a la axiología que nos jerarquiza y explica los valores que deben proyectar como si fueran faros, su luz para guiar por la senda adecuada al ser humano. O bien a los convencionalismos sociales que facilitan la convivencia pacífica.

De ahí deviene lo que debemos hacer jurídicamente en las tareas que llevemos a cabo. No cumplir con el derecho o violarlo produce consecuencias que pueden acarrear las sanciones; mas la juridicidad del derecho no está en el castigo sino en los valores que postula y que exige su realización.

Dicho esto tenemos que a cada actividad externa se aplica una norma pese a que no aparezca de momento o bien, en última instancia, que al no estar prohibida, está permitida por el derecho. 
El contenido lo da el campo de acción y no éste quien conforma a la norma. En otras palabras, todos los momentos de nuestra vida terrenal se encuentran regulados ineludiblemente por la ciencia del derecho. ${ }^{17}$

Ésta es mi concepción del mismo engarzado desde luego en los valores de la cultura cristiana occidental pero no reñida con otras concepciones jurídicas que postulen sus propios valores culturales pero que socialmente coincidan con las nuestras.

Con base en ello discrepo de las afirmaciones citadas textualmente del profesor Prosper Weil, pero coincido plenamente con sus conclusiones, particularmente con la primera y la tercera in fine.

Así derivamos que el derecho internacional, al ocuparse de regular las relaciones entre los miembros de la comunidad internacional, sean Estados o entidades dotadas de cierto grado de soberanía, comprende un capítulo que se ocupa particularmente de las relaciones con un contenido marcadamente económico.

\section{Campo de análisis}

Primero permítaseme precisar que al mencionar al derecho comercial me refiero necesariamente al mercantil pues conceptualmente es lo mismo. Hago esta consideración pues algunos autores lo denominan de modo indistinto más no señalan ninguna diferencia. ${ }^{18}$

Adentrándonos en el tema, tenemos que los actos y las actividades comerciales son prácticamente tan antiguas como el hombre y han evolucionado y diversificado constantemente. Se pueden ubicar entre acciones particulares o bien gubernamentales; internas o internacionales; o bien actos que trascienden, en su consideración y efectos, los límites fronterizos y a la regulación por el derecho.

Es más, se hacen presentes en las grandes empresas transnacionales cuyos actos pueden ser regulados por normas internas (locales), naciona-

17 El carácter que presenta el derecho como ciencia social es aceptado por la filosofía del derecho y aún por otras disciplinas del conocimiento. Así, el profesor Raúl Espinosa nos dice: "He querido precisar estas consideraciones acerca del sentido de la especie humana por la relación última que tiene con el sentido y el fin del derecho como una hechura del hombre... cuyo objeto es la satisfacción de la necesidades de la vida social, asegurar el mutuo respeto, la justicia, la libertad y en fin, la solidaridad y la paz entre los hombres. En “¿Qué es el derecho?”, Revista de Derecho Público, Universidad de Chile, Escuela de Derecho, núm. 11, 1970, p. 122.

18 Del latín cum, con, y merx, mercancía. 
les e internacionales. Tenemos también los acuerdos multilaterales y los regionales de comercio. En fin una gama muy basta y numerosa.

Si volteamos los ojos a la historia encontraremos qué prácticas e instituciones ancestrales se encuentran presentes en la actualidad. ${ }^{19}$ Sobre todo las características esenciales de las normas jurídicas comerciales permanecen inalterables por la sencilla razón de que mutatis mutandi, las razones meta-jurídicas que exigen su creación, son las mismas.

Al pasar lista a la historia de las relaciones internacionales, con frecuencia aparece el tema comercial pues ha sido y continua siendo el gran motor de las mismas y el hilo conductor de las relaciones humanas. ${ }^{20}$

Ocasionalmente esta motivación ha dado lugar a que se establezca una especie de hermandad entre comerciantes más allá de etnias, nacionalidades y religiones. Así surgieron los interdictos aplicables entre los comerciantes judíos denominados marrufia cuyo propósito era proteger con gentiles los negocios de judíos de la intervención de otros judíos, o los llamados "responsa" medievales tendientes a proteger los intereses y aún a las personas y familias de los comerciantes cristianos, árabes y judíos, como nos lo informa y explica el respetado doctor Boris Kozolchyk. ${ }^{21}$

Como se aprecia, la raíz del tema es fuerte y añosa, sus ramas gruesas y su vigor inacabable pues siguen apareciendo nuevos brotes al árbol. Empero no es mi propósito, como ya he consignado, ocuparme de todo lo jurídico-comercial, sino sólo de un sector, y dentro del mismo, del actual.

He fijado la atención en un momento histórico reciente como punto de partida o si se quiere, de referencia a la reflexión que nos ocupa y éste es el relativo al momento en que se crearon las reglas para ordenar y facilitar el desarrollo de la comunidad internacional al fin de la Segunda Guerra Mundial y las que han surgido derivadas de su aplicación.

Es referencia común mencionar a este esfuerzo como el "Sistema de Breton Woods" cuyos resultados fueron el Fondo Monetario Internacio-

19 Podemos mencionar que en el 1700 a. C., en el Código de Hamurabi se reglamentaba el préstamo con intereses, el contrato de comisión y las sociedades comerciales. Véase Szramkievicz, Romuald, Histoire du Droit des Affaires, París, Montchrestien, 1989, pp. 20 y 21.

20 Renouvin, Pierre, Historia de las relaciones internacionales, Madrid, Aguilar, 1969, 3 ts.

21 El derecho comercial ante el libre comercio y el desarrollo económico, México, MacGraw Hill, 1996, pp. 130-132; 138-140 y 310-312. 
nal, El Banco Mundial y el Acuerdo General de Aranceles Aduaneros y Comercio que mencioné al iniciar la presente charla.

Las tres entidades fueron origen de un conjunto de normas aceptadas por gran parte de los miembros de la comunidad internacional y que hoy continúan vigentes, regulando las interrelaciones comerciales y financieras prevalecientes en todo el mundo, aún más allá de las que se dan en los 148 miembros que componen la OMC.

Cabe señalar, como lo manifiesta John H. Jackson, que a través del sistema en cuestión se han evidenciado la interdependencia económica internacional contemporánea en donde el atributo tradicional del Estado moderno como es la soberanía, se ha puesto en jaque o al menos, ha sufrido una reevaluación, de lo que me ocuparé más adelante. ${ }^{22}$

Los estatutos de dichas instituciones son en esencia, tratados internacionales y como tales generadores de derechos y deberes jurídicos de observancia obligatoria.

Todos ellos permanecen en vigor y el GATT de carácter estrictamente comercial, ha dado origen a un sinnúmero de acuerdos, interpretaciones, protocolos y desde luego al surgimiento de la OMC, con su cauda de acuerdos laterales, tanto los multilaterales como los plurilaterales y desde luego de su cuatro anexos.

Para efectos meramente prácticos e ilustrativos, el cúmulo de documentos los podemos dividir en dos grupos: el primero formado por toda la historia y el acervo correspondiente del GATT que suman cerca de 200 instrumentos, y el segundo por la carta fundamental de la OMC integrada por 16 artículos y por los cuatro anexos compuestos a su vez por numerosos acuerdos. ${ }^{23}$

Los temas que son objeto de reglamento son los más destacados en las relaciones comerciales internacionales y solamente los mencionamos para dejar constancia de los mismos ya que su análisis sería interminable e innecesario.

22 Legal problems of internacional economic relations, West Publishing Co. EU, 1995. Del mismo autor: World Trade and the Law of GATT, The Miehie Company, 1969. Véase, asimismo, Bahla, Raj y Kennedy, Kenn, Word Trade Law, Lexis Law Publishing, 1998; Reyes Heroles, Jesús, La Carta de La Habana, México, EDIAPSA, 1948; Malpica de la Madrid, Luis, ¿Qué es el GATT?, México, Grijalbo, 1979.

23 Me ocupo del tema en mi libro Las relaciones comerciales multilaterales de México y el Tratado de Libre Comercio con la Unión Europea, Universidad Iberoamericana-UNAM, Instituto de Investigaciones Jurídicas, 2003. 
Así los grandes anexos se ocupan sobre el tráfico de mercancías en todos los órdenes, lo que significa el GATT de 1947, balanza de pagos, la aplicación de los artículos VI, VII, XVI, XXIV y otros. Agricultura, textiles, normas, barreras no arancelarias, medidas sanitarias, servicios, propiedad intelectual, salvaguardas y solución de controversias.

A esto debemos agregar el conjunto de dispensas, excepciones a la aplicación de la cláusula de nación más favorecida contenida en el artículo XXIV y en su complemento: el entendimiento relativo a la aplicación del artículo XXIV, a los que volveremos poco más adelante.

Prácticamente todos estos temas fueron objeto también de consideración en el TLCAN, cuya entrada en vigor se anticipó a la OMC.

Sin equivocarme puedo señalar que todas las relaciones comerciales generales se encuentran comprendidas y reguladas por este sistema multilateral; habida cuenta que bajo su manto se agrupan también los acuerdos comerciales regionales (ACR).

Por último será pertinente recordar que también la ONU se ha ocupado del tema del comercio internacional en los años sesenta, cuando pronunciara varias resoluciones, por ejemplo: la 1707 (XVI) del 19 de diciembre de 1961 y la 1785 (XVII) del 8 de diciembre de 1962, que dieran nacimiento a la Conferencia de las Naciones Unidas sobre el Comercio y el Desarrollo celebrada del 23 de marzo al 16 de junio de 1964.

En ella se formularon diversas recomendaciones que se agrupan en dos áreas: la correspondiente a diversos principios generales de comercio y las aplicables a la creación de un Consejo del Comercio y al desarrollo que diera pie a la conformación de la conferencia correspondiente (UNCTAD).

A medida que nos adentremos en este edificio de recios y antiguos muros pero con nuevas y modernas construcciones, nos encontramos con corredores y pasillos que pueden confundirnos.

Debemos por lo tanto reflexionar un momento y comprender que junto con las relaciones de contenido económico comercial se dan otras paralelas que están llamando la atención pero que tienen marcadas distinciones particulares.

Nos referimos especialmente a las normas jurídicas que regulan los procesos de integración económica, las que a juicio de respetados juristas y economistas tienen un espacio normativo propio, cuyo origen se da al conformarse la Comunidad Europea del Carbón y del Acero creada el 18 de abril de 1951. 
En efecto, el origen de estos movimientos económicos y políticos se encuentra también en la inquietud de los países de Europa Occidental al final de la Segunda Guerra Mundial por evitar otra conflagración mundial similar a las que se dieron en la primera parte del siglo $\mathrm{XX}$ y en constituir un equipo fuerte que pudiese actuar exitosamente, frente y con, el bloque soviético y con los Estados Unidos de América.

Retornando a concepciones políticas conocidas de antaño, se inicia así el proceso integracionista que ha caminado con evidente éxito y que por ahora ha hecho un alto en el camino ante la actitud de dos de sus iniciadores: Francia y Holanda, al rechazar el texto de la Constitución Europea elaborado de conformidad con la Convención de Niza, y aprobado en Bruselas el 17 y 18 de junio de 2003.

La integración europea sigue los pasos trazados por la doctrina tradicional y consagrada por Bela Balassa que parte de un propósito típicamente comercial, como es la agilización del comercio internacional en donde el abatimiento de los aranceles y el control de las barreras no arancelarias, se proyecta a otros campos en los que la política campea al grado que en su fase última los órganos comunitarios tienen toda autoridad sobre los nacionales en aquellas normas de su competencia. ${ }^{24}$

Siendo este fenómeno el más elaborado marca una pauta, y los demás experimentos en la materia se desarrollan hasta ahora exclusivamente sobre temas comerciales.

La globalización mundial actual se apoya indudablemente sobre estos sistemas por lo que las acciones llevadas a cabo están necesariamente reguladas por el derecho, tal como lo consideramos por tratarse de conductas externas de los Estados y de las instituciones creadas por los gobiernos.

Se distinguen en estas tareas al menos dos campos muy cercanos pero distintos: el que se ubica en el fenómeno de la integración ya mencionado y el que se ocupa de las relaciones comerciales que surgen tanto común y a una unión económica, apareciendo al final la integración económica total que ya comprende un enramado político con la necesaria limitación de los poderes soberanos de sus miembros. Véase The Theory of Economic Integration, Londres, 1961. 
en los fenómenos integracionistas como en los intercambios mercantiles. ${ }^{25}$

El primer grupo de normas regulatorias componen un nuevo capítulo del derecho internacional público que ha merecido diversos títulos. Para uno de los pioneros en el campo de referencia, Nicola Catalano, se trata del "derecho comunitario", término que se presume acuñado por la Corte de Justicia de las Comunidades (caso Costa 6/64) en razón "de que se considera como un derecho propio de las tres comunidades europeas originales". O bien el de "derecho de la integración" nombrado así por Pierre Pescatore, entre otros autores. ${ }^{26}$

En cuanto al segundo grupo podemos también distinguir entre las acciones que toman los Estados en forma unilateral para regular su comercio exterior que generalmente obedecen a intereses nacionales pero pueden también derivarse de convenciones internacionales, trátense de aquellos otros dictados por organismos comerciales multilaterales o bien de convenios internacionales de carácter particular como suelen ser los tratados de comercio, celebrados entre dos o más Estados para regular ciertos aspectos del tráfico común de carácter mercantil, o bien aquellos convenios que se inscriben dentro de las excepciones consideradas en el artículo XXIV del GATT y que se denominan "acuerdos comerciales regionales" (ACR).

Los primeros de estos acuerdos son los típicos y tradicionales que tratan algunos aspectos concretos de las relaciones entre dos o más Estados, y que se aplican tanto a los particulares como a los Estados cuando son propietarios de empresas económicas.

Los acuerdos regionales de comercio han sido denominados así a partir de 1996, al haberse creado el 6 de febrero el Comité de Acuerdos Comerciales Regionales, por Acuerdo del Consejo General de la OMC.

25 En efecto, existen otros rubros jurídicos cercanos al derecho económico, como lo es el "Derecho internacional del desarrollo" del que se ha ocupado largamente el distinguido jurista uruguayo doctor Hector Gros Espiel, Mohammed Bedjaoui y Alonso Gómez Robledo V. No nos ocuparemos del tema por exceder nuestro objetivo. Véase, respectivamente, de dichos autores: "Derecho internacional del desarrollo", Estudios de derecho económico..., cit., pp. 225 y ss.; Hacia un nuevo orden económico internacional, Salamanca, UNESCO, 1979; y "Notas sobre el llamado derecho internacional del desarrollo", Boletín Mexicano de Derecho Comparado, México, UNAM, Instituto de Investigaciones Jurídicas, año XX, núm. 60, 1987, pp. 919 y 920.

26 Véase Catalano, Nicola, Manual de derecho de las comunidades europeas, trad. de Marino Ayerra, Buenos Aires, Instituto para la Integración de América Latina, 1966; y Pescatore, Pierre, Derecho de la integración: nuevos fenómenos de las relaciones internacionales, trad. de Inés Carmen Matarasse, Buenos Aires, Instituto para la Integración de América Latina, 1973. 
Dicho comité fue establecido ante la proliferación de tratados de esta índole para vigilar que al amparo de las excepciones establecidas al artículo Io. del GATT, no se provocasen distorsiones a la reglamentación general y se desviasen de los propósitos liberalizadores del comercio.

Sin embargo en la práctica su tarea ha sido más positiva pues se han ocupado de precisar, aclarar e interpretar algunos puntos confusos o imprecisos tanto del artículo XXIV como del entendimiento relativo a su interpretación (ERI-XXIV, 1995) ${ }^{27}$ por lo que su tarea está resultando de gran utilidad dado el número tan creciente de acuerdos regionales, pues al presente año suman 300 aproximadamente, entre los que se encuentra el TLCAN.

Habrá que añadir a este conjunto de normas regulatorias obligatorias, las opiniones de las organizaciones especializadas que sin ser vinculantes, van creando derecho y las resoluciones arbitrales de los grupos especiales que funcionan conforme al Entendimiento de Solución de Diferencias (Anexo 2 de la OMC) pues sin duda su tarea al precisar la aplicación de los principios y reglas del GATT, de los acuerdos plurilaterales y de los multilaterales, engrosan esta nueva porción del derecho internacional.

Poco se ha explorado, pero asimismo merece nuestra atención la originalidad de un mecanismo de solución de diferencias creado en el TLCAN que rompe con ciertos principios tradicionales del derecho internacional como es el de la mediatez, pues permite que un particular sea una persona o una empresa, enderece en forma directa una demanda contra un Estado extranjero. Esto sucede con el procedimiento previsto en la sección B del capítulo XI relativo a conflictos por inversiones.

No se escapa a nuestro análisis la opinión fundada de que las sentencias, los laudos y aun las resoluciones de órganos internacionales de alta relevancia como pueden ser la Asamblea General de las Naciones Unidas o las del Consejo de Seguridad de la misma, no crean derecho per se pues el tema resuelto siempre será individual y los sujetos involucrados

27 Así se desprende de los documentos WT/REG/W/21 del 28 de noviembre de 1997; WT/REG/W21 Rev.1 y WT/REG/W/17/Rev. ambos del 5 de febrero de 1998; WT/REG/W/37 del 2 de marzo del 2000 y TN/RL/W/8/Rev.1 del 1o. de agosto del 2002. 
serán también únicos, por lo que se dice: "aplican por lo general el derecho existente, pero no pueden crear nuevo derecho". ${ }^{28}$

Sin embargo, la interpretación que se haga del derecho sí puede conformar una práctica reiterada que a la postre genere una cierta jurisprudencia al grado que quien litigue ante un tribunal internacional arbitral deberá preocuparse no sólo de las normas que fundamenten sus pretensiones sino también de conocer e invocar los precedentes referentes a las mismas.

Existen algunas otras causas de excepción a principios regulatorios de los actos de comercio que se dan por ejemplo cuando un gobierno los realiza en condición de particular (iure gestionis) y no como entidad pública (iure imperii), dándose el fenómeno de la "excepción a la excepción", pues no se podrá interponer la excepción de soberanía. ${ }^{29}$

\section{CARACTERÍSTICAS DE LAS NORMAS COMERCIALES INTERNACIONALES}

Para algunos autores como Szramkiewicz, las notas distintivas son las siguientes:

a) Su fuente es el acuerdo de voluntades, es una norma originada en la comunicación de las partes más que en las disposiciones gubernamentales.

b) Por ende suelen ser poco formalistas, en contraste con las normas del derecho, tal como sucedió en Roma, lo que provocó la elaboración de un derecho especial aplicable a las acciones de un ciudadano romano y un extranjero denominado Jus Gentium.

c) Asimismo su informalidad deviene de que en sus orígenes poco intervinieron reglas y ritos religiosos, por lo que se le califica como un derecho "laico".

d) Las disposiciones comerciales tienden a ser flexibles y por ende menos generales pues se modifican según los acontecimientos lo exigen. ${ }^{30}$

28 Herdegen, Matthias, Derecho internacional público, México, UNAM-Fundación Konrad Adenauer, 2005, pp. 161-165.

29 Véase Friedman, Wolfgang, op. cit, pp. 212 y 410 a 412; y Cruz Miramontes, Rodolfo, $L a$ ley norteamericana de inmunidad del Estado soberano, México, IMCE y Academia de Arbitraje y Comercio Internacional, 1981.

30 Szramkiewicz, Romuald, op. cit., pp. 18-32. 
Nuestro conocido profesor Prosper Weil coincide con algunas de las menciones anteriores y nos proporciona otras notas. Así tenemos que:

La norma tradicional es por su naturaleza misma "generalizadora"... La norma del derecho económico en cambio aspira a ser "individualizadora".

En la fase de su elaboración, la norma de derecho internacional económico escapa al formalismo clásico y goza de una extraña libertad.

La regla de derecho internacional económico está caracterizada por una enorme maleabilidad.

Por una parte, en efecto, la directiva y la recomendación van adquiriendo cada vez más amplitud en detrimento de la decisión. ${ }^{31}$

$\mathrm{Al}$ intento de perfilar las características individuales de la norma jurídica en cuestión, me parece interesante el rasgo distintivo que los profesores Fernández Rozas y Sánchez Lorenzo le atribuyen al "derecho del comercio internacional" en un estudio sobre el tema ${ }^{32}$ consistente en que los principales participantes son las personas jurídicas que pueden ser desde las entidades públicas (empresas), como parte del Estado comerciante, las empresas o sociedades multinacionales, los organismos internacionales especializados (las instituciones del sistema del Bretton Woods) hasta en situaciones excepcionales, el individuo, la persona que puede ser contraparte en un juicio, de un Estado soberano.

Como se desprende en todo lo anterior, el punto de los sujetos o destinatarios de estas normas jurídicas resultan disímbolos.

El elemento "privatístico", como lo denominan algunos autores, es concurrente en las diversas opiniones no solamente de analistas del tema, sino aún de cierto sector especializado de la ONU, como se deriva de la Resolución de la Asamblea General del 20 de diciembre de 1965 [2102 $(\mathrm{XX})]$ en la que se manejan tres elementos a propósito del derecho del comercio internacional:

a) Objeto: regular las relaciones comerciales internacionales

b) Carácter de las relaciones: privado o sea de derecho privado

c) Carácter uniforme ${ }^{33}$

31 Weil Prosper..., cit, pp. 178-190.

32 Derecho del comercio internacional, Madrid, Eurolex, S. L., 1996, pp. 43 y 44.

33 Citado y comentado por Fernández Rozas y Sánchez Lorenzo, Derecho del comercio internacional..., cit., p. 40. 
La razón de mencionar esta referencia, con la que no concordamos plenamente, estriba en que se resalta la presencia importante de lo privado junto con lo público.

Esta nota viene a resultar característica notable del desarrollo del derecho económico en sus actuales expresiones tal como lo ha resaltado el Tribunal de Justicia de las Comunidades Europeas en varias ocasiones, particularmente en la sentencia del caso Gend and Loos al referirse expresamente al hecho de que entre los objetivos de la comunidades europeas se comprende no sólo la acción de los Estados sino de los ciudadanos cuyo concurso es necesario. ${ }^{34}$

Tal preocupación se repite en el Tratado de la Unión Europea (Maastricht, 7 de febrero de 1992, y Ámsterdam, 2 de octubre de 1997), al afirmar que "las decisiones se tomen de la forma más próxima posible a los ciudadanos de acuerdo con el principio de subsidiaridad". ${ }^{35}$

Así aparece que en las manifestaciones tanto en las reglas comerciales actuales como en el derecho comunitario a las que nos referimos anteriormente, se presentan los mismos rasgos característicos.

Algunos autores, como el profesor Gerard Farjat ya mencionado, apunta otro elemento particular y consiste en que la vinculación original entre el derecho comercial y el derecho civil clásico sigue presente. Esto es que las instituciones y principios del mismo son aplicados en las operaciones cotidianas mercantiles, lo que rechaza la tesis que el derecho económico y el comercial son dos ramas autónomas del derecho internacional. Podemos ratificar lo ya dicho en cuanto a que así como el derecho económico se perfiló con fuerza entre los años veinte a cincuenta, campea la presencia del derecho económico-comercial a partir de los años cincuenta: "El derecho mercantil internacional es la norma más difícil de definir del derecho internacional público porque, si bien es cierto que durante decenios y hasta siglos han habido transacciones comerciales internacionales, hace muy poco han sido consideradas del dominio del derecho internacional público". ${ }^{36}$

Otra consideración obligada será el asomarnos a las fuentes del derecho del comercio internacional.

34 Citada por Ortiz Ahlf, Loretta, "Derecho comunitario y derecho internacional", Revista de Derecho de la Unión Europea, núm. 4, 2003, p. 14.

35 Mangras, Araceli (ed.), "Preámbulo párrafo 10", Tratado de la Unión Europea, 6a. ed., Madrid, Tecnos, 1998.

36 Friedman, Wolfgang, op. cit., p. 210. 


\section{Las fuentes}

El punto de partida necesariamente será el correspondiente a las fuentes del derecho internacional público, las que están comprendidas en el artículo 38 del Estatuto de la Corte Internacional de Justicia que son: los tratados, la costumbre, los principios generales de derecho reconocidos por las naciones civilizadas (termino anacrónico), las decisiones jurídicas y la doctrina de los publicistas de mayor reconocimiento.

En consecuencia debemos de tomar en cuenta esta relación concreta de la creación de las normas en cuestión.

Sin embargo hemos precisado que estamos manejando tanto al concepto del derecho económico como a una parte del mismo, esto es al comercio, por ende debemos examinar si tienen algunas fuentes particulares o propias.

Necesariamente debemos indagar en el campo del derecho económico internacional primeramente, para de ahí partir hacia las áreas específicas de nuestra inquietud.

Hasta mediados de la década de los ochenta, las fuentes se ubicaban claramente conforme al sistema económico imperante en la época: unas eran las propias del área soviética o de economía dirigida y otras las de los países capitalistas.

Los estudios elaborados sobre el particular se ocupan con precisión de ambas diferencias. Al caer el muro de Berlín, y con ello el sistema soviético, dejó de tener sentido tal distinción.

En cambio la presencia de la integración europea, con sus instituciones fuertes y cerradas, provocaron que el orden jurídico que las regula se impusiese sobre algunas áreas de los sistemas nacionales y con ello, se convirtiesen en fuentes generales de derecho.

En términos generales se distinguen dos tipos de fuentes: las primarias y las derivadas, conformando a las primeras los tres tratados constitutivos de la Comunidad Europea y los segundos por (las) "normas contenidas en los actos adoptados por las instituciones en aplicación de esos tratados".

Junto a ellas existen otras fuentes más amplias vinculadas al derecho comunitario destacando las interpretaciones del tribunal y junto con ellas los acuerdos y el llamado "derecho complementario".37 
Como bien dice la maestra Loretta Ortiz, miembro de número de nuestra academia: "El derecho comunitario europeo se integró no únicamente por normas internacionales, sino también por otro conjunto de normas cuyo origen no proviene de la fuentes del derecho internacional público". ${ }^{38}$

Por el papel único que juegan ciertas decisiones de la Corte de Justicia cuando no solamente resuelven una diferencia sino interpretan y crean derechos comunitarios, citamos la opinión del doctor Joel Ridau: "Los tres tratados constitutivos le encargan a la Corte de Justicia, asegurar el respeto al derecho al interpretar y aplicar los tratados constitutivos". 39

Tenemos así que el derecho comunitario o de la integración se acunó, como ya hemos dicho, a finales de los años cuarenta, y sus primeros pasos los dio en la senda del comercio internacional al conformar una unión aduanera como es la Comunidad Europea del Carbón y del Acero.

Al mismo tiempo que surgía esta nueva expresión jurídica, se activaba un orden jurídico tan antiguo como el hombre y éste es el derecho comercial.

La continuidad a través del tiempo, de reglas tan añosas, ha sido constante y ha conformado una tradición presente en los usos y costumbres mercantiles.

No será por demás recordar que la noción de fuente nos ofrece una imagen fluvial, pues el término significa tanto el sitio donde se origina la corriente como las causas que la conforman, tal como lo ha manifestado el profesor berlinés Paul Heilborn. ${ }^{40}$

Esto ayudará a que precisemos los orígenes de las normas del comercio internacional y conozcamos si presentan diferencias específicas de su género próximo como es el derecho económico internacional.

Sin duda que lo anterior nos aproxima a la existencia de la lex mercatoria y su recepción por los sistemas jurídicos nacionales, así como su eventual consagración formal en los textos internacionales tal como lo encontramos en la Convención de Viena de 1980 relativa a la Venta Internacional de Mercaderías.

38 Ortiz Alfh, Loretta, op. cit., p. 16.

39 Le Droit de L'Union Européenne, París, 1998, p. 63.

40 Les Sources du Droit International, Recueil des Cours, París, Académie de Droit International, Librairie Hachette, 1926, p. 11. 
El concepto de lex mercatoria que frecuentemente se invoca en los textos de derecho mercantil no sólo refleja un conjunto de prácticas y de convicciones sobre su validez sino también cambios que la práctica de los comerciantes ofrece.

En consecuencia es válido preguntarnos si la concepción actual de la misma ha recogido los usos y costumbres derivados de la reordenación del comercio internacional a partir de los años cincuenta.

Esta fuente de derecho que por definición es dinámica, reta sin duda a la concepción formal y cerrada comprendida en el artículo 38 de la Corte Internacional de Justicia y es de invocarse por su pertinencia, la afirmación que compartimos del internacionalista Manuel Becerra Ramírez quien sostiene que: "Este artículo se debe ver como un punto de referencia de las decisiones de la CIJ pero no como una enumeración cerrada... es necesario incorporar a las fuentes tradicionales... otras fuentes como son los actos unilaterales, las resoluciones de los organismos internacionales y los actos ejecutivos". ${ }^{41}$

Habida cuenta de lo anterior, la pesquisa iniciada nos lleva a estimar si la práctica mercantil internacional nos permite suponer la existencia de una lex mercatoria actualizada.

Sin duda la respuesta a nuestra pregunta la encontraremos primeramente en las reglas arbitrales aplicables en los conflictos comerciales al consignar entre los ordenamientos que los juzgadores deben tomar en cuenta para pronunciar su fallo, a la lex mercatoria.

Según los profesores Craigg, Park y Paulsson al estudiar el tema, deberán considerarse tres posibilidades:

a) La lex mercatoria es un orden legal autónomo.

b) La lex mercatoria constituye sólo un cuerpo de reglas suficientes para decidir una disputa o

c) Solamente debe considerarse como complementaria de una ley nacional.

Conscientes de que el campo a estimar se ha reducido al terreno de las disputas comerciales, su relevancia no puede negarse pues el arbitraje

41 "Las nuevas fuentes del derecho interno y su aplicación en el derecho internacional", Méndez Silva, Ricardo (coord.), Derecho y seguridad internacional, México, UNAM, 2005, pp. 586 y 587. Véase, asimismo, a Barberis, Julio A., Formación del derecho internacional, Buenos Aires, Ábaco de Rodolfo Depalma. Véase también Ortiz García, Antonio, "La jurisprudencia de los tribunales internacionales y el desarrollo del derecho internacional", Revista de derecho español y americano, Madrid, año XIII, IIa. época, 1968. 
ha sido por antonomasia el que los conflictos mercantiles han aplicado para su resolución y esta práctica cada vez más la encontramos presente tanto en los conflictos entre particulares como entre entidades públicas.

Es más, uno de los mayores éxitos atribuidos a la OMC, lo constituye la institucionalización del arbitraje como el mecanismo propio para resolver los conflictos que surjan entre los miembros de la misma (Entendimiento para la Solución de Diferencias. Anexo 2). ${ }^{42}$

Con cuidado debemos observar este punto pues la invocación a la lex mercatoria como fuente útil para resolver una desavenencia comercial, nos puede mostrar dos cosas: la constatación de una práctica o de un uso observado por los comerciantes y la aplicación como precedente de la interpretación seguida por los árbitros como evidencia de una convicción generalizada.

La conclusión a que arriban los autores citados es que se trata de usos seguidos por los comerciantes que los consideran obligatorios y las decisiones arbitrales deben estimarse en su justa medida como reflejo de realidades económicas y disposiciones acordes con las necesidades del comercio internacional. ${ }^{43}$

Las CCI ha sido el foro en el que se han expresado a través de la práctica del arbitraje comercial, estas opiniones que plasman diversos puntos de vista sobre la práctica constante de las negociaciones comerciales internacionales.

Desde luego que no es la única que hace eco de dichas prácticas, ya que la Uncitral también trabaja arduamente en la materia y eventualmente ha realizado codificaciones sobre temas comerciales y arbitrales, como por ejemplo con la Ley Modelo sobre Arbitraje Comercial Internacional de 1985.

A estos esfuerzos debemos unir los de otras instituciones también de carácter internacional como sucede con el Instituto Internacional para la Unificación del Derecho Internacional Privado (Unidroit) quien en 1994 diera a conocer el texto firmado en Roma denominado Principios sobre los Contratos Comerciales Internacionales.

42 Pace, Virgile, La Organisation Mundiale du Commerce et le Renforcement de la Reglamentation Juridique des echanges Commerciaux Intenationaux, París, L'Harmattan, 1999, pp. 388 y 402 .

43 International Chamber of Commerce Arbitration, 3a. ed., Oceana Publications Inc., 2000, pp. 623, 633, 638 y 639. Asimismo, véase Redferon, Alan y Hunter, Martin, Law and practice of International Commerce Arbitratión 2a. ed., London, Sweet and Maxwell, 1991, pp. 117-122. 
Llama la atención que en el preámbulo del documento se establezca que: "Estos principios pueden aplicarse cuando las partes hayan acordado que el contrato se rija por los principios 'generales del derecho', la 'lex mercatoria' o expresiones semejantes".

Lo anterior, como podemos derivar, pretende asimilar los citados principios a la lex mercatoria, lo que desde luego nos indica que hay una conciencia entre los estudiosos de que el fenómeno evoluciona y asimismo pone en evidencia el interés y la inquietud que existe sobre la materia. ${ }^{44}$

En el mismo orden de ideas ubicamos a la Convención Interamericana sobre Derecho Aplicable a los Contratos Internacionales que fuera aprobada por la Organización de Estados Americanos (OEA), el 17 de marzo de 1994.

Por último mencionaremos a las disposiciones legales que los Estados crean para regular su comercio exterior que ya hemos mencionado. Generalmente suelen estar acordes con los dictados del GATT y de la OMC, por lo que siendo su fuente el Poder Legislativo nacional, participa de las reglas multilaterales.

Su importancia corre pareja con el mercado interno del país que las establece, pero al fin de cuentas las consideramos para los efectos de nuestro estudio como nacionales. ${ }^{45}$

El profesor José Luis Siqueiros, reconocido internacionalista y miembro distinguido de nuestra academia, sostuvo en su discurso de contestación al correspondiente de ingreso del maestro César Sepúlveda que: "En cuanto a las fuentes de esta ciencia... debe mencionarse la existencia de nuevas fuentes cuyas definiciones están en proceso de elaboración; con carácter ejemplificativo podemos referirnos a los nuevos mecanismos normativos que surgen con las normas imperativas de derecho internacional general o ius cogens, (y) a las normas supranacionales dentro de los procesos de integración económica". ${ }^{46}$

44 En 1996 se llevó a cabo en la ciudad de México un seminario de análisis de los citados principios entre las universidades Nacional Autónoma de México y Panamericana, a iniciativa de esta última. Tuve el honor de participar y de haberme ocupado del arbitraje al que se refieren el artículo 1.10 y el capítulo 7. Véase Contratación internacional, México, Universidad Panamericana-UNAM, Instituto de Investigaciones Jurídicas, 1998.

45 Véase Witker, Jorge y Hernández, Laura, Régimen jurídico del comercio exterior de México, México, UNAM, Instituto de Investigaciones Jurídicas, 2002 pp. 10-12.

46 Sepúlveda, César, El lugar del derecho internacional en el universo jurídico, México, Porrúa, 1989, pp. 63 y 64. En el mismo sentido, se pronuncia el profesor de la Universidad de Co- 
Habiendo ya revisado las opiniones autorizadas de especialistas en la materia así como la situación que guarda actualmente el entorno jurídico que regula a las transacciones comerciales internacionales, debemos consignar algunas respuestas posibles a las interrogantes planteadas en nuestra indagación, para lo cual ofrecemos las siguientes:

\section{CONCLUSIONES}

Primera. No encontramos que exista propiamente un cuerpo normativo absoluto y cerrado que integre un capítulo sobre el derecho del comercio internacional que sea oponible y que lo haga distinto al derecho económico internacional, a tal grado que constituya una disciplina autónoma.

Segunda. Sin embargo se han ido decantando numerosas normas jurídicas derivadas de la aplicación de sistemas legales en el ámbito económico que nos indican una corriente propia hacia las transacciones y ordenamientos del comercio internacional.

Tercera. Este conjunto de normas comerciales se insertan en el orden tradicional del comercio y están enriqueciendo tanto a órdenes legales de dicho ámbito como a la lex mercatoria internacional.

Cuarta. Por lo tanto su lugar está a nuestro entender, por ahora, en el derecho económico internacional que constituye un capítulo del derecho internacional público.

Quinto. Lo anterior no está reñido con la consideración que se merece, de referirnos a este conjunto de disposiciones como un derecho del comercio internacional en ciernes, aún no fraguado pero presente y en constante evolución. 


\section{ANEXO}

\section{CONTESTACIÓN AL DISCURSO DE INGRESO A LA ACADEMIA MEXICANA DE JURISPRUDENCIA Y LEGISLACIÓN DEL DOCTOR RODOLFO CRUZ MIRAMONTES (25-X-05)}

Señor presidente de la Academia Mexicana de Jurisprudencia y Legislación Señores directivos de la Academia Señor académico Rodolfo Cruz Miramontes Distinguidos académicos y visitantes:

Me es muy grato a nombre de nuestra academia el contestar, aunque sea brevemente, el discurso de ingreso a la misma como académico de número, del distinguido jurista doctor Rodolfo Cruz Miramontes. Rodolfo, como le llamamos quienes nos preciamos de ser sus amigos, ha pronunciado una brillante disertación sobre las normas que rigen el comercio internacional, su importancia en el contexto de dicho ámbito y la posible existencia de un derecho del comercio internacional como disciplina autónoma.

Sin embargo, antes de hacer algunos comentarios sobre su excelente exposición, quisiera dejar constancia de algunos de los antecedentes biográficos del académico ingresante. Obtuvo Licenciatura en Derecho en la Facultad de Derecho de la UNAM y también el Doctorado en Derecho en la Universidad de Madrid. Ha sido profesor de derecho internacional público en la Universidad Nacional Autónoma de México, en otras instituciones académicas de la capital de la república y de varias ciudades del interior del país, así como colaborador del Instituto de Estudios Diplomáticos "Matías Romero" de la Secretaría de Relaciones Exteriores. Es autor de diversos artículos especializados publicados en México y diferentes países del mundo; asimismo, de varios libros en los que aborda las relaciones comerciales multilaterales, el Tratado de Libre Comercio con la Unión Europea, el TLCAN celebrado con los Estados Unidos y Canadá, la legislación restrictiva del comercio internacional, el arbitraje y otras temáticas. Ha sido recipiendario de premios y reconocimientos de distintas asociaciones y se ha involucrado en la negociación de diversos tratados de libre comercio celebrados por nuestro país.

Con estos datos curriculares ¿quién podría dudar de su idoneidad para reflexionar sobre el derecho económico y su gradual influencia en el marco jurídico del comercio internacional? 
Incursionando en la temática de su discurso el nuevo académico nos recuerda que el derecho internacional, al regular las relaciones entre los miembros de la comunidad de las naciones, ya sean Estados o entidades dotadas de cierto grado de soberanía, incluye un apartado que se ocupa de las relaciones con un contenido económico. A este respecto nos rememora los esfuerzos a nivel internacional que se hicieron hace casi medio siglo en el llamado Sistema de Breton Woods y que cristalizaron en el Fondo Monetario Internacional, el Banco Mundial y el Acuerdo General de Aranceles Aduaneros y Comercio. El surgimiento posterior de la Organización Mundial de Comercio vino a consolidar el sistema financiero internacional.

Los estatutos que rigen a las anteriores instituciones son en esencia tratados internacionales y como tales son parte del derecho de gentes. El Acuerdo General, mejor conocido por sus siglas en inglés como el GATT, y la OMC han propiciado la formalización de un numeroso grupo de acuerdos laterales. Ello, sin perjuicio de mencionar la importancia de los acuerdos comerciales regionales y de los tratados de libre comercio que han proliferado por todo el orbe. Todos estos esfuerzos a nivel multilateral pueden asumir diversas formas; además de las convenciones internacionales, hay que sumar los actos legislativos supranacionales y las leyes modelo.

No obstante, la diversidad de culturas y de tradiciones jurídicas todavía impide una armonización en el ámbito contractual del comercio. En tanto que algunas corrientes confluyen a un ulterior desarrollo de los "usos y costumbres en el comercio internacional" a través de cláusulas y contratos modelo, los resultados de esos esfuerzos han sido fragmentarios.

Sin embargo, como el doctor Cruz Miramontes también lo apunta al final de su discurso, el Instituto Internacional para la Unificación del Derecho Privado, mejor conocido por su sigla como Unidroit, ha seguido una nueva ruta. El instituto, que tiene su sede en Roma, propugna por la formulación de reglas generales aplicables a los contratos mercantiles, es decir, lo que en la terminología jurídica estadounidense podría considerarse un restatement de los principios que uniformemente se aplican en este ámbito.

Como también el nuevo académico lo señala, el propio preámbulo de los Principios del Unidroit subraya que los mismos pueden aplicarse cuando las partes hayan acordado que el contrato se rija por los principios generales de derecho, la lex mercatoria o expresiones semejantes. El doctor Cruz Miramontes y el de la voz aportaron sus reflexiones y comentarios sobre dichos Principios del 
Unidroit en un seminario auspiciado por la Universidad Nacional Autónoma de México y por la Universidad Panamericana ${ }^{47}$ en 1997. La disertación de Rodolfo está referida al arbitraje comercial y a su función en la aplicación de los citados principios. La ponencia de su servidor se orienta a un análisis comparativo entre los mismos y la Convención Interamericana sobre el Derecho Aplicable a los Contratos Internacionales.

Ambos concluimos que la gradual interdependencia entre los países y el proceso globalizador en el comercio internacional van conduciendo a sus agentes económicos hacia fórmulas de principios uniformes que ofrecen soluciones armónicas en caso de divergencia. Asimismo, opinamos que los Principios de Unidroit no son sólo un marco jurídico para la celebración de contratos comerciales internacionales, sino criterios y luces para quien se ocupe de actos regidos por los mismos.

La segunda edición de los Principios de Unidroit se publicó en 2004, diez años después de la primera publicación de los mismos. Transcurrida una década pudo comprobarse que recibieron la aprobación generalizada de los mercantilistas a nivel mundial; asimismo, que no habían suscitado problemas significativos en su aplicación cuando las partes habían convenido en que sus acuerdos fueren regidos por ellos.

Si bien es cierto que la edición 2004 contiene pocas reformas de fondo al articulado de 1994, la creciente práctica de la contratación electrónica requirió que la última edición adicionara o modificara el texto del articulado anterior concerniente (entre otros capítulos) a disposiciones generales y de formación de los contratos, además de nuevos apartados en materia de extinción de obligaciones por compensación, cesión de derechos contractuales y plazos de prescripción. El objetivo básico de la última edición fue la de introducir una nueva normatividad en temáticas de interés para la comunidad internacional del comercio. El propósito del Instituto de Roma sigue siendo el ofrecer un instrumento de reglas generales que las partes puedan voluntariamente adoptar en sus contratos o ser susceptibles de aplicarse en el caso de que dichas partes no hubieren elegido el derecho que debe regular aquellos.

El nuevo académico también nos recuerda que muchos tratadistas de derecho internacional público dan cabida en sus textos a la presencia del factor económico en el desarrollo de dicha rama del derecho, uniéndose a la opinión generalizada de que existe un importante espacio formado por el derecho económico

47 Ambas ponencias fueron incluidas en el libro Contratación internacional, editada por las dos instituciones académicas en 1988, pp. 217-228 y pp. 253-264. 
internacional. La realidad es que una nueva corriente se ha ido decantando en el contorno tradicional del comercio para enriquecer el ámbito de la lex mercatoria internacional y de otras fuentes del derecho de gentes, incluyendo las normas supranacionales en los procesos de integración económica. Lo anterior nos lleva al campo de los contratos mercantiles internacionales y es en esta área donde la ponencia del nuevo académico numerario nos ilustra.

La importancia de este tema y su necesaria regulación ha sido reconocida por México; como lo indica Rodolfo, nuestro país propuso y apoyó la Carta de los Derechos y Deberes de los Estados para que fuera adoptada por las Naciones Unidas el 12 de diciembre de 1974. La promulgación de la Ley sobre la Aprobación de Tratados Internacionales en Materia Económica en septiembre de 2004 es otro ejemplo de la importancia que México otorga a la promoción de la transparencia en las relaciones comerciales internacionales.

Sin perjuicio de lo anterior coincidimos con el doctor Cruz Miramontes en la primera de sus conclusiones, cuando hace una referencia a ese conjunto de normas mercantiles que rigen el comercio internacional. Afirma que todavía no existe un cuerpo normativo absoluto que integre una rama independiente y constituya per se una disciplina autónoma; por ahora, creemos que sigue siendo parte del derecho económico internacional. Tal vez con el transcurso del tiempo, en el mundo de la economía globalizada en que vivimos, la normatividad que regula este sector alcance una emancipación de su tronco tradicional, pero todavía no llegamos a esa etapa.

Para concluir esta breve contestación al discurso de ingreso del doctor Cruz Miramontes, quisiera reiterarle al colega y al amigo mi felicitación por todos los logros obtenidos en su trayectoria académica y confiar en que sus aportes al derecho económico internacional continúen ilustrándonos en el seno de esta noble institución.

Gracias por su atención.

José Luis Siqueiros*

México D. F. 25 de octubre de 2005

* Miembro numerario, sitial núm. 35 de la academia. 